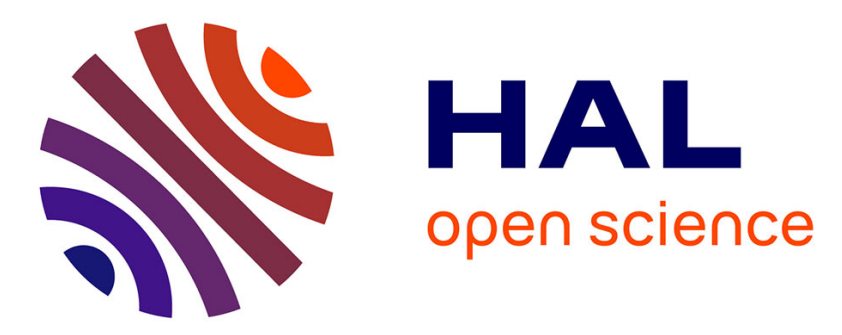

\title{
Active vibration isolation of electronic components by piezocomposite clamped-clamped beam
}

\author{
Yann Meyer, Manuel Collet
}

\section{To cite this version:}

Yann Meyer, Manuel Collet. Active vibration isolation of electronic components by piezocomposite clamped-clamped beam. Mechanical Systems and Signal Processing, 2011, 25, pp.1687-1701. 10.1016/j.ymssp.2010.12.015 . hal-02300132

\section{HAL Id: hal-02300132 \\ https://hal.science/hal-02300132}

Submitted on 20 Nov 2019

HAL is a multi-disciplinary open access archive for the deposit and dissemination of scientific research documents, whether they are published or not. The documents may come from teaching and research institutions in France or abroad, or from public or private research centers.
L'archive ouverte pluridisciplinaire HAL, est destinée au dépôt et à la diffusion de documents scientifiques de niveau recherche, publiés ou non, émanant des établissements d'enseignement et de recherche français ou étrangers, des laboratoires publics ou privés. 


\title{
Active vibration isolation of electronic components by piezocomposite clamped-clamped beam
}

\author{
Y. Meyer ${ }^{\mathrm{a}, *}$, M. Collet $^{\mathrm{b}}$ \\ a Institut Superieur de Mecanique de Paris (SUPMECA Paris), LISMMA/Structures, 3 rue Fernand Hainaut, 93407 Saint Ouen Cedex, France \\ ${ }^{\mathrm{b}}$ FEMTO ST Institute, Department LMARC, UMR 6174, 25000 Besançon, France
}

The sensitive electronic components used in military and aerospace applications endure some intense vibrations. These vibrations have some disturbing effects on the stability and on the service life of these devices. So, protecting these elements becomes a major economic and strategic stake. Vibration isolation can be applied to different levels of the on-board systems. Indeed, it is advisable to isolate electronic components either at the rack level or at the board level or at the component level. In this paper, the last solution is chosen because of low moving masses which imply low control energies.

An active suspension system is located between the host board and the sensitive element to be isolated. This designed control system uses a simple Integral Force Feedback strategy. This vibration isolation control is stable for its collocated version and does not need a numerical model of the system to be controlled. Robustness of the system is asymptotically guaranteed. The proposed isolation device, made of alumina for passive structure and made of PZT and PVDF for transducing layers, is experimentally tested. Experimental performances are compared with theoretical performances.

\section{Introduction}

Vibration isolation is necessary in two broad classes of problems:

- A vibrating element is fixed on a structure. Mechanical waves propagate through this whole structure. Thus, they can damage the different sensitive elements of the structure or reduce their service life.

- A sensitive element is fixed on a vibrating structure. So, vibrations can modify operating points of this element but also strongly damage it.

The passive solution is the simplest way to achieve vibration isolation. Several passive techniques are studied in the literature by using elastomer materials [1], by using shape memory alloys [2,3] or by modifying mechanical impedances [4]. The passive suspension, sketched in Fig. 1, is considered.

The transmissibility of the system, i.e. the relationship between the acceleration of the mass $\left(\ddot{W}_{s}\right)$ and the acceleration imposed to the support $\left(\ddot{W}_{u}\right)$ is written in Laplace's variables:

$$
T_{\ddot{W}_{s}, \ddot{W}_{u}}=\frac{(\ddot{W})_{s}}{(\ddot{W})_{u}}=\frac{s \cdot C+K}{s^{2} \cdot M+s \cdot C+K}
$$

\footnotetext{
* Corresponding author.

E-mail addresses: yann.meyer@gmail.com (Y. Meyer), manuel.collet@univ-fcomte.fr (M. Collet).
} 


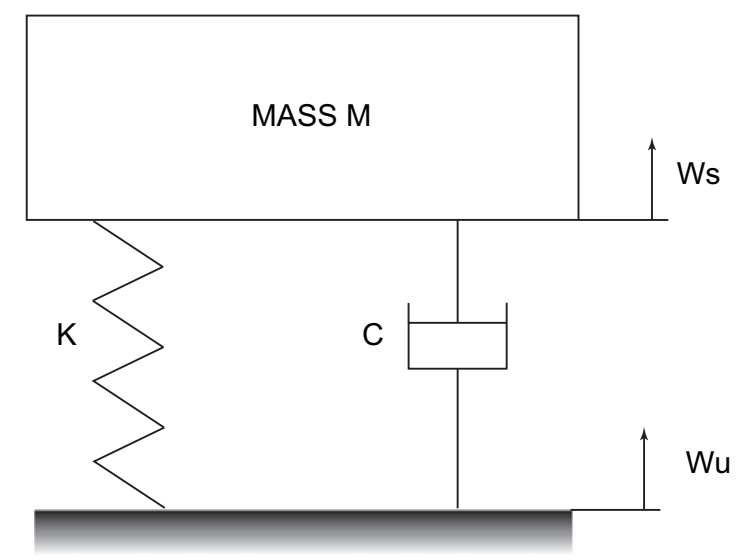

Fig. 1. One-degree-of-freedom system.

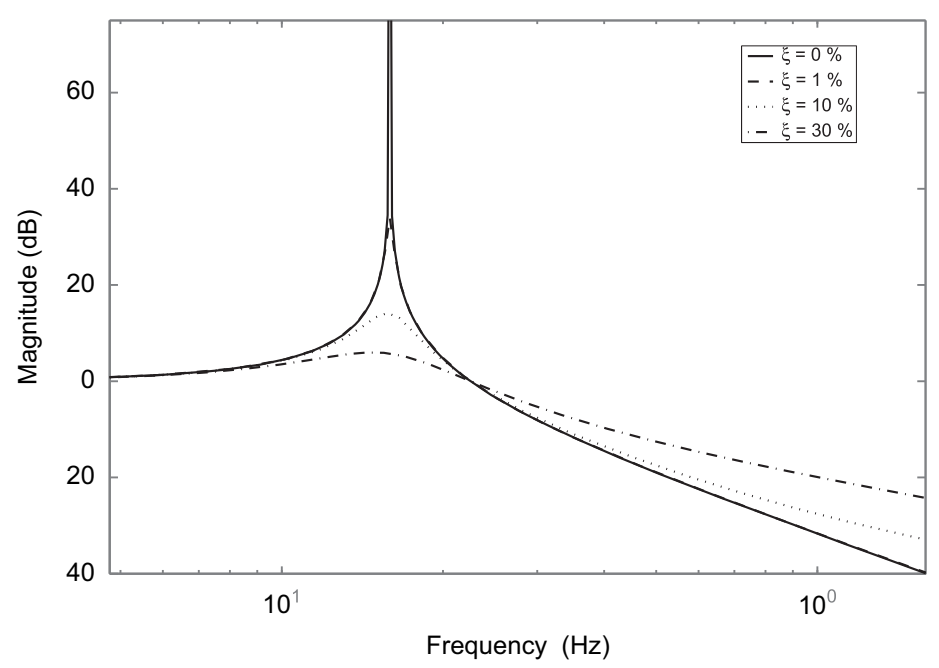

Fig. 2. Transfer function evolution of a one-degree-of-freedom system for different values of $\xi=(C / 2) \sqrt{(1 / M K)}$.

where $K$ is the stiffness of the suspension $\left(\mathrm{N} \mathrm{m}^{-1}\right), M$ the mass of the structure $(\mathrm{Kg}), C$ the damping coefficient induced by the suspension $\left(\mathrm{Kg} \mathrm{s}^{-1}\right)$ and $s$ the Laplace's variable.

The objective of any suspension is obviously to limit the acceleration of the system to be isolated in the excitation frequency bandwidth. The behavior of the system is observed in Fig. 2, where different transfer functions are plotted for different damping ratio values $\xi=(C / 2) \sqrt{(1 / M K)}$.

As shown in Fig. 2, this system presents a modal resonance peak that is to say an increasing of the acceleration of the system to be isolated in a narrow frequency bandwidth. Obviously, the modal peaks decrease when the damping ratio of the system increases. Consequently, the resonance amplification decreases and the sensitive mass stability increases in the narrow frequency bandwidth around the considered eigenfrequencies. However, this effect also results in the reduction of a high frequency filtering decay rate. Indeed, this high frequency decay rate evolves from $-40 \mathrm{~dB} / \mathrm{decade}$, when no structural damping is considered in the suspension, to $-20 \mathrm{~dB} /$ decade limit for high structural damping ratios, $\xi$. Thus, it results a bad isolation in high frequency range. Then, it becomes necessary to lower the cut-off frequency to increase the high frequency isolation capability of the suspension. This modification is performed by limiting the stiffness of the connection what involves a loss of stability in low frequencies. Ultimately, the traditional mechanical compromise is in the ratio between the stiffness and the damping ratio of the connection [5].

A best mechanical compromise can be obtained by using an active control process [5]. Sky-hook control is the simplest and the most common control strategy [6]. This isolation method can be stable and robust in its collocated version. The idea is to actively introduce, in the mechanical connection, a viscous damper rigidly fixed to a Galilean coordinate system. The design of this controller is based on an absolute sensing signal such as the acceleration, the transmitted force, the absolute velocity or the absolute displacement. Studies of various sky-hook-type strategies are broadly proposed in the literature [7].

The constant miniaturization of electronic components essential with electronic boards such as the frequency generators, the vibrating gyroscopes and certain accelerometers generates two major difficulties. On the one hand, the size of the soldered connection points is strongly reduced and so the yield strength of these soldered connection points is reached. On the other hand, the dimension reduction of these elements fatally involves the reduction of their useful mass. 
Then, these electronic components become very sensitive to the external noise and become inefficient and inaccurate. Consequently, the measurement accuracy is lost in signal noise level.

There are various methods to avoid these limitations. Indeed, it is possible to stabilize the sensitive components at level of the racks containing carrying electronic cards. Generally, this solution is obtained by using passive isolation strategies. A second solution involves stabilizing at level of the boards. It is possible to apply some active isolation strategies by using piezoelectric patches [8-10]. The last solution is to control the electronic components themselves. This paper examines this method. The principal idea is to create "small isolation islands" to individually isolate each sensitive component [11]. The control electronics already presents onto the electronic boards is exploited. The isolation structure will be integrated into the design phase of the electronic circuits. The used control law is founded on a classical collocated "sky-hook" strategy with an internal sensor.

The objective of this study is to design, manufacture and test a isolation meso-structure, so as to prove an active vibration isolation feasibility for a vibration isolation device. The paper is organized as follows. Section 2 describes the operation of the studied active suspension, the experimental device and the way to manufacture it. In Section 3, modeling of the active suspension is provided and an experimental characterization is achieved. This section is a base for the numerical development of the control architecture in Section 4. In the following section, experiments are achieved to clearly set the validity of the control strategy and, thus, of our designed active suspension. These experimental results are compared with the numerical ones. Finally, concluding remarks are discussed.

\section{Design concept of the active suspension}

\subsection{Operation principle}

The basis of an active isolator is the addition of an "active" function to a traditional suspension. The objective is to decrease the resonance peak amplitude without degradation of the high frequency decay rate. The framework of the isolation device constitutes the passive isolator. Sensors and actuators are added to the suspension, as shown in Fig. 3. The sensor monitors the vibratory state of the suspended mass. This strategy is efficient for an absolute information: the acceleration, the reaction force and, eventually, the absolute displacement or the absolute speed. Different variants, based on the measurement type, can be performed [7]. Then, it makes it possible to create an actuator input signal via a controller. Of course, this controller is a function of the transmitted information but also of the reaction type produced by actuators.

A one-single-degree-of-freedom system is considered again. The equation of motion of the system is given by

$$
M \cdot \ddot{W}_{s}+C \cdot \dot{W}_{s}+K \cdot W_{s}=F_{\text {ext }}+u_{\text {control }}
$$

where $F_{e x t}=C \cdot \dot{W}_{u}+K \cdot W_{u}$ is the external excitation $(N)$ and $u_{\text {control }}$ the control force $(N)$.

The control aim is to attenuate the resonance peaks without modifying the high frequency decay rate. The signal of the chosen sensor is proportional to the acceleration. Thus, the sensor signal is integrated to achieve the desired effect. The control law is related to a "proportional-integral" method [12]. The idea is to actively introduce, in the mechanical connection, a viscous damper rigidly fixed to a Galilean coordinate system. In our case, the central sensor is an accelerometer. So, as presented in Eq. (3), a PI control can be sufficient with an acceleration measurement to control the suspension resonance. If a relative measurement is used and a PI control introduced, the suspension resonance will be damped but the high frequency decay rate will be degraded.

Within the active control loop, the strategy is called "sky-hook" damper [5].

$$
u_{\text {control }}=-G \cdot \int y \cdot d t=-G \cdot \int \alpha \cdot \ddot{W}_{s} \cdot d t=-G \cdot \alpha \cdot \dot{W}_{s}
$$

where $G, y$ and $\alpha$ are the control gain $\left(\mathrm{Kg} \mathrm{s}^{-1}\right)$, the sensor signal $\left(\mathrm{m} \mathrm{s}^{-2}\right)$ and the strictly positive sensor gain.

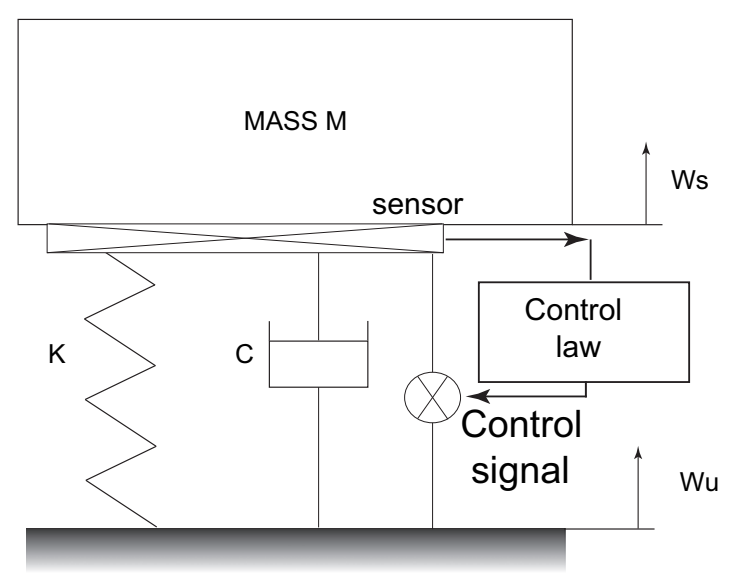

Fig. 3. Principle scheme of a "local" active isolator. 
The "sky-hook" strategy has two major advantages. This strategy is robust. In other words, even if the structure changes because of ageing or natural system drift, the control remains powerful. In addition, no matter what the structure is simple or complex or if an acceleration or force sensor is used, the "sky-hook" strategy can be stable under the conditions exposed in [5]. In our case, the internal dynamics of the sensor is very high in frequency with respect to the suspension frequency. So, the stability is guaranteed. The disadvantage of the "sky-hook" is the non-optimality of the control law. Thus, it becomes imperative to optimize the location of the sensors and actuators on the structure so as to obtain good control results.

\subsection{Experimental device}

An alumina clamped-clamped beam, as shown in Fig. 4, is used as a basic passive structure on which the element to be isolated is located [13]. The active function is conferred to the structure by two piezoelectric actuators and one piezoelectric sensor located on the top face of the beam. These active parts of the system are founded on PZT layers for the actuating parts and on PDVF layer for the sensing part. The PVDF layer constitutes the support of the component to be isolated which is, in our example, a little mass, made of steel.

In this application, the direct and opposite piezoelectric effects are used. So as to simultaneously allow the detection and activation, a wire system is used. The actuators are placed close to boundaries of the beam and their length is optimized in order to obtain the maximum action force on the first bending mode [14,15]. The sensor and the element to be isolated are located at the middle of the suspension. A sensor output signal, mainly proportional to the acceleration endured by the component, is obtained.

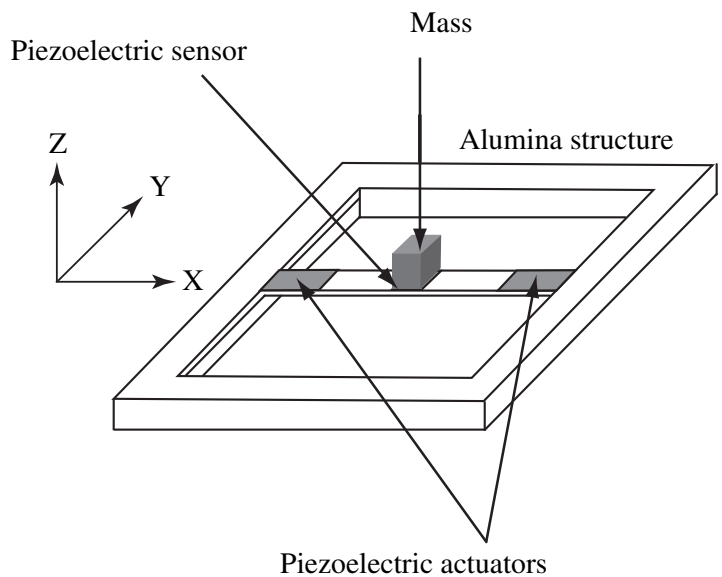

Fig. 4. Structure of the suspension.

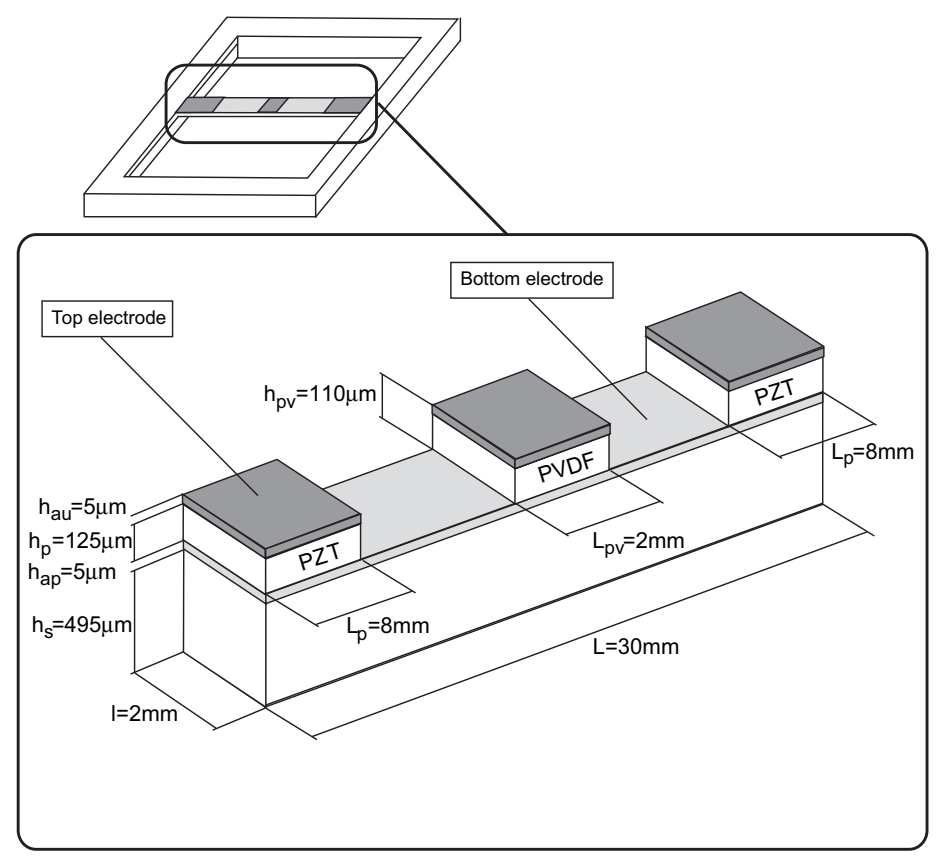

Fig. 5. Configuration of the studied structure. 
Table 1

Dimensions of the beam and the piezoelectric materials.

\begin{tabular}{ll}
\hline$L(\mathrm{~mm})$ & Length of beam \\
$l(\mathrm{~mm})$ & Width of beam \\
$L_{1}=L_{2}(\mathrm{~mm})$ & Length of PZT layers \\
$L_{p v}(\mathrm{~mm})$ & Length of PVDF layer \\
$h_{s}(\mu \mathrm{m})$ & Thickness of beam \\
$h_{p}(\mu \mathrm{m})$ & Thickness of PZT layers \\
$h_{p v}(\mu \mathrm{m})$ & Thickness of PVDF layer \\
$M_{s}(\mathrm{mg})$ & Mass to be isolated \\
\hline
\end{tabular}

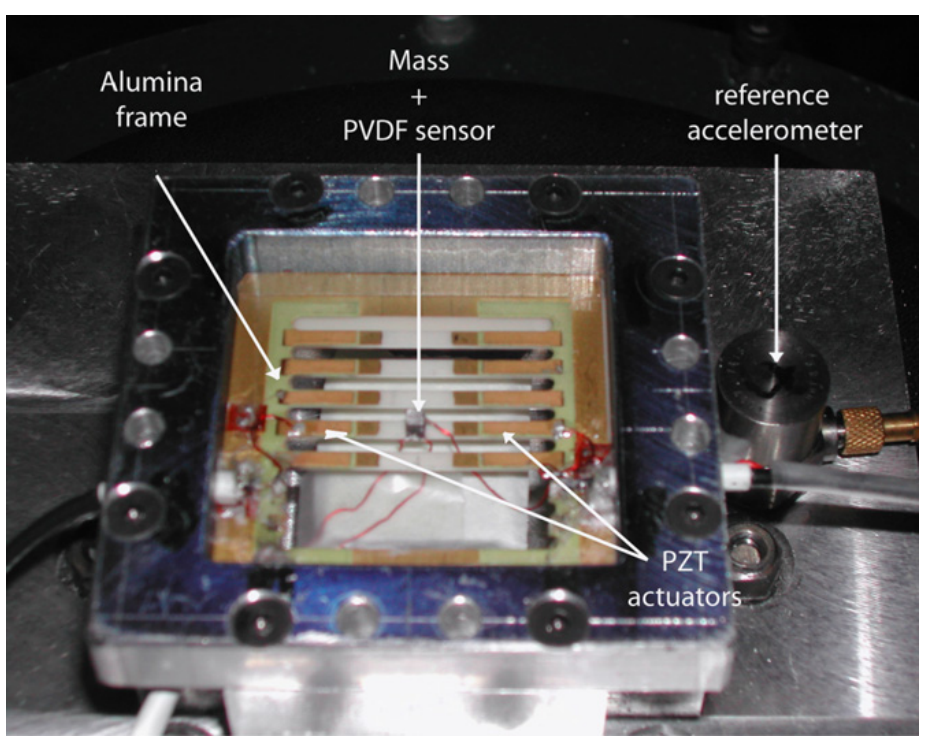

Fig. 6. Close-up of the alumina structure.

\subsection{Manufacturing of the active suspension}

As indicated in Fig. 5 and in Table 1, the suspension device is a piezocomposite clamped-clamped beam, made of $495 \mu \mathrm{m}$ thick alumina, $125 \mu \mathrm{m}$ thick PZT for the actuators with one electrode of $5 \mu \mathrm{m}$ thick in gold and $110 \mu \mathrm{m}$ thick PVDF for the sensor. The beam dimensions are $30 \mathrm{~mm}$ long and $2 \mathrm{~mm}$ width. The actuators are $8 \mathrm{~mm}$ long and the sensor $2 \mathrm{~mm}$ long. The transducers have the same width as the host beam. The electronic component to be protected is glued on the central part of the meso-system. This sensitive element is mechanically replaced by a cubic steel mass of 2 mm side weighting $62.4 \mathrm{mg}$. Let us note that this value is representative of the masses of a real electronic meso-component.

The device manufacturing is achieved in laboratory, as explained in [16]. The bottom electrode is a Ag-Pd layer. The actuators are hard PZT layers. They are obtained by a screen-printing process [17] of $\mathrm{PbSr}\left(\mathrm{Zr}_{0.455} \mathrm{Ti}_{0.455} \mathrm{~W}_{0.036} \mathrm{Sn}_{0.036} \mathrm{Mn}_{0.028}\right)$ powder. The top electrode of the actuators is a pulverized gold layer. The sensor is a PVDF layer glued on the middle of the beam.

For a screen-printing process, a paste is prepared. It constitutes by an active material in the proportion of $80 \mathrm{wt} \%$ and an organic vehicle which is constituted by a binder, a solvent, a plasticizer and a dispersing agent. The second step is the paste printed onto alumina substrate on which the bottom electrode is already metallized. Finally, the structure is submitted to a thermal process with two stages. The first one burns out all organic components of the film and the second one is a sintering step in order to densify the deposited film and ensure its adhesion onto the substrate.

In Fig. 6, the one-degree-of-freedom isolation structure, used for experiments, is shown.

\section{Modeling of the active suspension}

An analytical method is used for the modeling. For simplicity, the piezoelectrically actuated beam and the "sensor and mass" unit are separately studied. Finally, the modeling of the whole suspension device is obtained by the assembly of these two parts.

For the modeling, Euler-Bernoulli assumptions are used. The electrodes are neglected. The polling axis is along the $Z$-axis in the coordinate system described in Fig. 4. Only the first natural bending mode is considered. This bending motion is only in the $(\vec{x}, \vec{z})$ plan. The considered materials are assumed isotropic for the bending motion. The last assumption is rather strong for the piezoelectric parts of the structure. It well knows that the shear effects act on the modeling accuracy $[18,19]$. But, for a simple and quick modeling, this assumption is kept. 


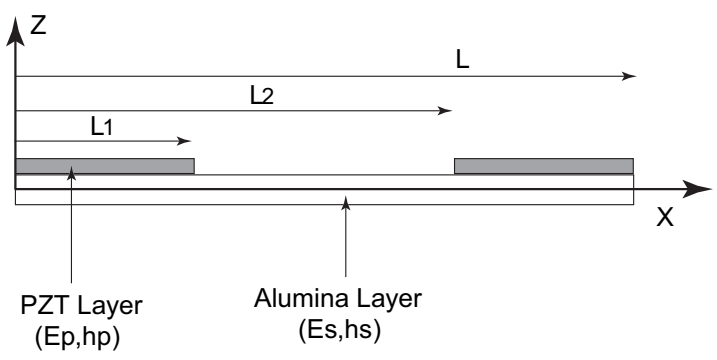

Fig. 7. Host piezoelectrically actuated beam.

\subsection{Modeling of the host piezoelectrically actuated beam}

The host piezoelectrically actuated beam, shown in Fig. 7, is considered. The modeling of an Euler-Bernoulli beam with piezoelectric patches is widely exploited in the literature [20-22]. So, relationship (4) expresses the beam equation of motion:

$$
\bar{\rho}(x) \ddot{w}(x, t)+E I(x) \frac{\partial^{4} w(x, t)}{\partial x^{2}}=\lambda V_{a}(t)\left[\dot{\delta}(x)-\dot{\delta}\left(x-L_{1}\right)+\dot{\delta}\left(x-L_{2}\right)-\dot{\delta}(x-L)\right]+p(x, t)
$$

with

$$
\left\{\begin{array}{l}
\bar{\rho}=\frac{\left(h_{s} \bar{\rho}_{s}+h_{p} \bar{\rho}_{p}\right)}{h_{s}+h_{p}} \\
\left.E I=\left(\frac{E_{s} h_{s} l\left(h_{s}^{2}+3 h_{p}^{2}\right)}{12}+\frac{E_{p} h_{p} l\left(h_{s p}^{2}+3 h_{s}^{2}\right)}{12}\right)-\frac{\left(E_{p}-E_{s}\right)^{2} h_{s}^{2} h_{p}^{2} l}{4\left(E_{s} h_{s}+E_{p} h_{p}\right)} \quad \forall x \in\right] 0, L_{1}[\cup] L_{2}, L[ \\
\lambda=\left(\frac{h_{s}}{2}-\frac{\left(E_{p}-E_{s}\right) h_{s} h_{p}}{2\left(E_{s} h_{s}+E_{p} h_{p}\right)}\right) l e_{31}
\end{array}\right.
$$

and

$$
\left\{\begin{array}{l}
\bar{\rho}=\bar{\rho}_{s} \\
\left.E I=\frac{E_{s} h_{s}^{3} l}{12} \quad \forall x \in\right] L_{1}, L_{2}[ \\
\lambda=\frac{h_{s}}{2}
\end{array}\right.
$$

where $\bar{\rho}$ is the linear mass density $\left(\mathrm{Kg} \mathrm{m}^{-1}\right), w(x, t)$ the transverse beam displacement $(\mathrm{m}), E_{p}$ Young's modulus of the alumina beam $\left(\mathrm{N} \mathrm{m}^{-2}\right), E_{s}$ Young's modulus of the PZT layer $\left(\mathrm{N} \mathrm{m}^{-2}\right), h_{s}$ the thickness of the alumina beam, $h_{p}$ the thickness of the PZT layer, $l$ the width of the beam, $e_{31}$ the PZT electromechanical coupling coefficient, $\delta$ the spatial derivative of the Dirac delta function, $V_{a}$ the control voltage $(\mathrm{V})$, and $p(x, t)$ the linear density of the external excitation $\left(\mathrm{N} \mathrm{m}^{-1}\right)$.

The associated mechanical boundary conditions are

$$
\begin{cases}w(x, t)=\frac{\partial w(x, t)}{\partial x}=0 & \text { for } x=0 \\ w(x, t)=\frac{\partial w(x, t)}{\partial x}=0 & \text { for } x=L\end{cases}
$$

\subsection{Modeling of the sensor}

The PDVF layer, the mass to be isolated and the Galilean coordinate system, presented in Fig. 8, is considered.

The constitutive equation for a PDVF layer with a polling axis along the $z_{1}$-axis and electrodes in the $\left(\overrightarrow{x_{1}}, \overrightarrow{y_{1}}\right)$ plan can be written as [20-22]

$$
D_{3}=e_{31} S_{1}+e_{33} S_{3}+\varepsilon_{33}^{S} E_{3}
$$

$D_{3}, S, \varepsilon^{S}, e$ and $E_{3}$ are, respectively, the electric displacement along the $\overrightarrow{z_{1}}$ axis $\left(\mathrm{C} \mathrm{m}^{-2}\right)$, the strain vector by using the compressed matrix notation (IEEE standard), the dielectric permittivity coefficient at constant strain (F $\mathrm{m}^{-1}$ ), the PVDF electromechanical coupling coefficient $\left(\mathrm{C} \mathrm{m}^{-2}\right)$ and the electric field along the $\overrightarrow{z_{1}}$ axis $\left(\mathrm{V} \mathrm{m}^{-1}\right)$. 


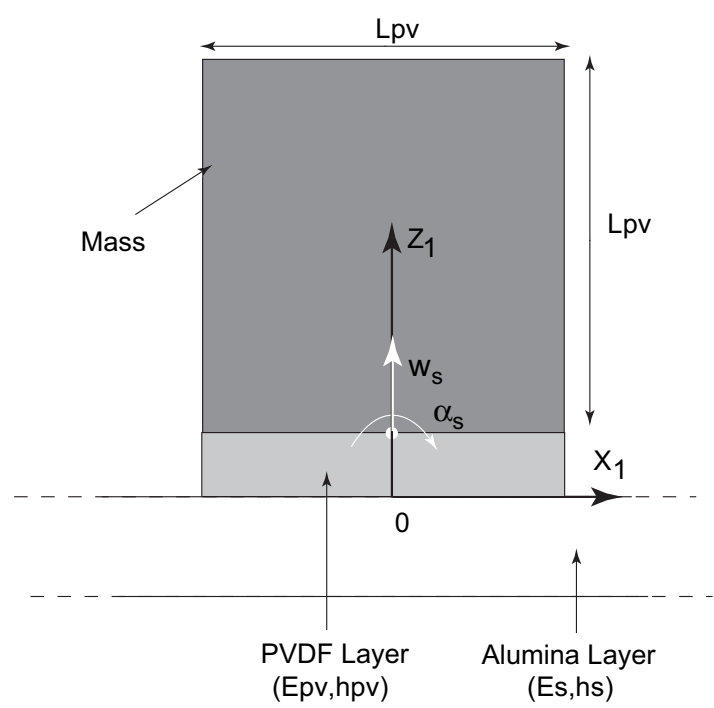

Fig. 8. Studied sensor.

Because the first natural bending mode of the host beam is considered, that is to say a pure bending motion, the strain along the $\overrightarrow{x_{1}}$ direction, in the PDVF layer, can be expressed by

$$
S_{1}=a z_{1}+b
$$

$a$ and $b$ are the values to be identified thanks to the boundary conditions.

At the top surface of the alumina beam, where the PVDF layer is assumed perfectly bonded, the strain along the $\overrightarrow{x_{1}}$ axis is given by

$$
S_{1}=-\frac{h_{s}}{2} \frac{\partial^{2} w\left(x_{1}, t\right)}{\partial x^{2}} \text { for } z_{1}=0
$$

At the top surface of the PDVF beam, the connection with the mass is assumed perfect. As the mass is perfectly rigid in the studied frequency bandwidth, the strain along the $\overrightarrow{x_{1}}$ axis is given by

$$
S_{1}=0 \text { for } z_{1}=h_{p v}
$$

By combining Eqs. (10) and (11), the strain along the $\overrightarrow{x_{1}}$ direction can be expressed as

$$
S_{1}=\frac{h_{s}}{2} \frac{\partial^{2} w\left(x_{1}, t\right)}{\partial x^{2}}\left(\frac{z_{1}}{h_{p v}}-1\right)
$$

To model the sensor, the strain of the PDVF layer is considered linear with respect to the $z_{1}$-axis. This assumption is correct because the first natural mode of the beam is studied and the sensor length is very low with respect to the beam length. So, the strain along the $\overrightarrow{z_{1}}$ direction can be written as Eq. (13) with respect to the mass motions, $w_{s}$, the displacement along the $\overrightarrow{z_{1}}$ axis $(\mathrm{m})$, and $\alpha_{s}$, the rotation around the $\overrightarrow{y_{1}}$ axis (rad).

$$
S_{3}=\frac{\left(w_{s}(t)+x_{1} \alpha_{s}(t)\right)-w\left(x_{1}, t\right)}{h_{p v}}
$$

By substituting Eqs. (12) and (13) into Eq. (8) and by considering an electric potential linear in the thickness direction of the PVDF layer, the following equation is obtained.

$$
D_{3}=e_{33} \frac{w_{s}(t)+x \alpha_{s}(t)-w\left(x_{1}, t\right)}{h_{p v}}-\varepsilon_{33}^{S} \frac{U}{h_{p v}}
$$

where $U=V\left(z_{1}=h_{p v}\right)-V\left(z_{1}=0\right)$.

The electric charge, collected on the top electrode of the sensor $\left(z_{1}=h_{p v}\right)$, is expressed as

$$
q(t)=\int_{S_{\text {electrode }}} D_{3} d S=l \int_{-L_{p v} / 2}^{L_{p v} / 2} D_{3} d x_{1}
$$

By substituting relationship (14) into (15), electric charge (16) is obtained

$$
q(t)=l L_{p v}\left[\frac{e_{33}}{h_{p v}}\left(w_{s}-\frac{1}{L_{p v}} \int_{-L_{p v} / 2}^{L_{p v} / 2} w\left(x_{1}, t\right) d x\right)-\frac{\varepsilon_{33}^{S}}{h_{p v}} U\right]
$$




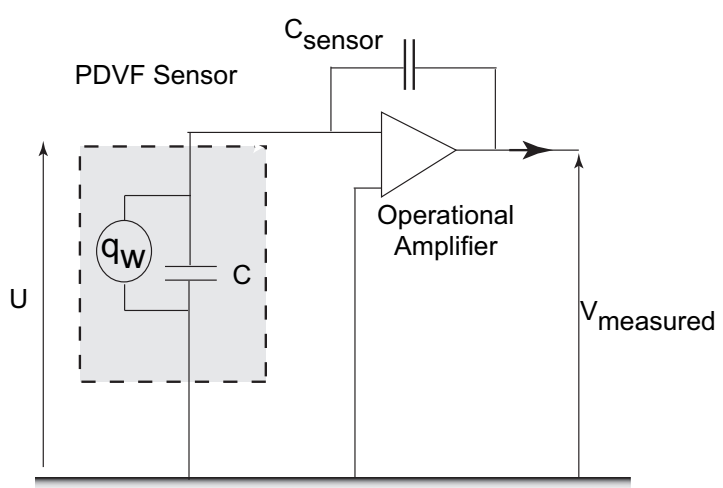

Fig. 9. Equivalent electric scheme of the PVDF sensor connected to a conditioning amplifier.

At the right-hand term of Eq. (16), the first part of the equation is related to the crushing, along the $z_{1}$-axis, of the PVDF layer due to the mass. The second part is the equivalent electric charge of the piezoelectric patch due to the voltage $U$ applied to the equivalent electric capacity of the piezoelectric patch, $C=l \varepsilon_{33}^{S} L_{p v} / h_{p v}$.

The sensor, connected to a conditioning amplifier, can be electrically modeled as shown in Fig. 9. So, Eq. (17) expresses the amplifier output voltage with respect to the output electric charge of the PDVF layer,

$$
V_{\text {measured }}=\frac{q(t)}{C_{\text {sensor }}}
$$

Moreover, due to the conditioning amplifier properties, the patch electrodes are short-circuited, so $U=0$. Thus, Eq. (18) is obtained by combining Eqs. (17) and (16).

$$
V_{\text {measured }}=\frac{l L_{p v}}{C_{\text {sensor }}}\left[\frac{e_{33}}{h_{p v}}\left(w_{s}-\frac{1}{L_{p v}} \int_{-L_{p v} / 2}^{L_{p v} / 2} w\left(x_{1}, t\right) d x_{1}\right)\right]
$$

\subsection{Global modeling}

The first natural bending mode of the host beam is considered. So, for simplicity, the transverse displacement, $w(x, t)$, is expressed as a projection on the first modal shape function

$$
w(x, t)=\phi_{1}(x) \eta_{1}(t)
$$

where $\phi_{1}(x)$ are the normalized modal shape function of the first natural mode and $\eta_{1}(t)$ the time-dependent modal coordinate of the first natural mode.

When substituting Eq. (19) into Eqs. (4) and (18), the equation system can be expressed by considering boundary conditions and by using modal decomposition

$$
m_{1} \ddot{\eta_{1}}(t)+k_{1} \eta_{1}(t)=\lambda V_{a}(t)\left[-\dot{\phi}_{1}\left(L_{1}\right)+\dot{\phi}_{1}\left(L_{2}\right)\right]+f(x, t) \Longleftrightarrow \ddot{\eta_{1}}(t)+\omega_{1}^{2} \eta_{1}(t)=\frac{\lambda V_{a}(t)}{m_{1}}\left[-\dot{\phi}_{1}\left(L_{1}\right)+\dot{\phi}_{1}\left(L_{2}\right)\right]+f(x, t)
$$

where

$$
\begin{aligned}
& m_{1}=\int_{0}^{L} \bar{\rho}(x)\left(\phi_{1}(x)\right)^{2} d x \\
& k_{1}=\int_{0}^{L} E I(x)\left(\frac{\partial^{2} \phi_{1}(x)}{\partial x^{2}}\right)^{2} d x \\
& \omega_{1}^{2}=\frac{k_{1}}{m_{1}} \\
& V_{\text {measured }}=\frac{l L_{p v}}{C_{\text {sensor }}}\left[\frac{e_{33}}{h_{p v}}\left(w_{s}-\frac{1}{L_{p v}}\left(\int_{-L_{p v} / 2}^{L_{p v} / 2} \phi_{1}\left(x_{1}-\frac{L}{2}\right) d x_{1}\right) \eta_{1}(t)\right)\right]
\end{aligned}
$$

The PDVF layer and the mass to be isolated can be modeled by a one-degree-of-freedom system, excited by its base. The PVDF layer is a plate in compression. Its equation of motion can be written as

$$
M_{s} \ddot{w}_{s}+\frac{E_{p v} l L_{p v}}{h_{p v}}\left(w_{s}-\frac{1}{L_{p v}}\left(\int_{-L_{p v} / 2}^{L_{p v} / 2} \phi_{1}\left(x_{1}-\frac{L}{2}\right) d x_{1}\right) \eta_{1}(t)\right)=0
$$


$E_{p v}$ is PVDF Young's modulus and $M_{s}$ the mass of the element to be isolated. Consequently, by combining Eqs. (21) and (22), Eq. (23) is obtained.

$$
V_{\text {measured }}=-\frac{M_{s} e_{33}}{C_{\text {sensor }} E_{p v}} \ddot{w}_{s}
$$

Consequently, the PVDF sensor measures the absolute acceleration endured by the mass to be isolated.

To model the interaction between the host beam and the structure composed of the sensor and the mass to be isolated, Eqs. (20) and (22) have to be combined. The external forces are assumed null. By using the third Newton's law and a base displacement due to a shaker, modeled by a one-degree-of-freedom system, the set of Eqs. (24) is written as

$$
\left\{\begin{array}{l}
M_{s} \ddot{w}_{s}+\frac{E_{p v} l L_{p v}}{h_{p v}}\left(w_{s}-\frac{1}{L_{p v}}\left(\int_{-L_{p v} / 2}^{L_{p v} / 2} \phi_{1}\left(x_{1}-\frac{L}{2}\right) d x_{1}\right) \eta_{1}(t)\right)=0 \\
\ddot{\eta_{1}}(t)+\omega_{1}^{2}\left(\eta_{1}(t)-w_{d}\right)-\frac{E_{p v} l L_{p v}}{h_{p v} m_{1}}\left(w_{s}-\frac{1}{L_{p v}}\left(\int_{-L_{p v} / 2}^{L_{p v} / 2} \phi_{1}\left(x_{1}-\frac{L}{2}\right) d x_{1}\right) \eta_{1}(t)\right) \\
=\frac{\lambda}{m_{1}}\left[-\dot{\phi}_{1}\left(L_{1}\right)+\dot{\phi}_{1}\left(L_{2}\right)\right] V_{a}(t) \\
m_{d} \ddot{w}_{d}+k_{d} w_{d}+m_{1} \omega_{1}^{2}\left(w_{d}-\eta_{1}(t)\right)=f_{d}
\end{array}\right.
$$

where $w_{d}$ is the displacement of the shaker $(\mathrm{m}), m_{d}$ the mass of the shaker $(\mathrm{Kg}), k_{d}$ the stiffness of the shaker $\left(\mathrm{N} \mathrm{m}{ }^{-1}\right)$ and $f_{d}$ the force experienced by the shaker mass $(\mathrm{N})$.

The dynamic system of the suspension device is formulated by the set of Eqs. (24). Thanks to the material properties, presented in Table 2, and the device dimensions, presented in Table 1, a numerical model can be expressed. Moreover, the studied modal shape function of the piezocomposite beam is assumed equal to the alumina beam. Indeed, the thickness of the PZT layer are too thin and PZT Young's modulus is too low compared to alumina Young's modulus, to strongly modify the beam dynamic behavior.

So, the normalized first natural mode shape of a clamped-clamped beam is expressed as [23]

$$
\phi_{1}(x)=\cosh \left(\alpha_{1} x\right)-\cos \left(\alpha_{1} x\right)-\frac{\cosh \left(\alpha_{1} L\right)-\cos \left(\alpha_{1} L\right)}{\sinh \left(\alpha_{1} L\right)-\sin \left(\alpha_{1} L\right)}\left(\sinh \left(\alpha_{1} x\right)-\sin \left(\alpha_{1} x\right)\right)
$$

where

$$
\alpha_{1}^{4}=\frac{12 \rho_{s} \omega_{1}^{2}}{E_{s} h_{s}^{2}}=\left(\frac{4.73}{L}\right)^{4}
$$

So, a numerical reduced state-space model of the suspension is built with the voltage applied to the actuators and the base displacement as input signals and the sensor signals and the absolute acceleration endured by the sensitive element as output signals. The initial damping ratio of the beam is assumed to be equal to $0.1 \%$. The natural frequency of the shaker is approximatively $30 \mathrm{~Hz}$. The moving mass of the shaker is equal to $10 \mathrm{Kg}$.

The state-space representation can be expressed as Eq. (27), according to Eqs. (24), (25) and (23) and different numerical parameters of the system:

$$
\left\{\begin{array}{l}
\dot{w}_{s} \\
\dot{\eta}_{1} \\
\dot{w}_{d} \\
\ddot{w}_{s} \\
\ddot{\eta}_{1} \\
\ddot{w}_{d}
\end{array}\right\}=A\left\{\begin{array}{c}
w_{s} \\
\eta_{1} \\
w_{d} \\
\dot{w}_{s} \\
\dot{\eta}_{1} \\
\dot{w}_{d}
\end{array}\right\}+B\left\{\begin{array}{c}
f_{d} \\
V_{a}(t)
\end{array}\right\}
$$

\section{Table 2}

Material properties of the beam and the piezoelectric layers.

\begin{tabular}{lllr}
\hline & Alumina & PZT & PVDF \\
\hline Young modulus $(\mathrm{GPa})$ & 305 & 54 & 2.5 \\
Mass density $\left(\mathrm{Kg} \mathrm{m}^{-3}\right)$ & 3900 & 7260 & 1780 \\
Piezo coefficient $e_{31}\left(\mathrm{C} \mathrm{m}^{2}\right)$ & - & -6.48 & 0.073 \\
Piezo coefficient $e_{33}\left(\mathrm{C} \mathrm{m}^{2}\right)$ & - & - & -0.105 \\
Permittivity $\varepsilon_{33}^{S}\left(10^{-11} \mathrm{~F} \mathrm{~m}^{-1}\right)$ & - & - & 9 \\
\hline
\end{tabular}


with

$$
A=\left[\begin{array}{cccccc}
0 & 0 & 0 & 1 & 0 & 0 \\
0 & 0 & 0 & 0 & 1 & 0 \\
0 & 0 & 0 & 0 & 0 & 1 \\
-1.46 e 12 & 1.55 e 13 & 0 & 0 & 0 & 0 \\
7 e 10 & -7.4 e 11 & 986.8 e 8 & 0 & 62.8 & 0 \\
0 & 1.3 e 6 & -1.92 e 6 & 0 & 0 & 0
\end{array}\right]
$$

and

$$
B=\left[\begin{array}{cc}
0 & 0 \\
0 & 0 \\
0 & 0 \\
0 & 0 \\
0 & 0.19 \\
0.1 & 0
\end{array}\right]
$$

The equation of observation can be written as

$$
\left\{\begin{array}{c}
V_{\text {measured }} \\
\ddot{w}_{s}
\end{array}\right\}=C\left\{\begin{array}{c}
w_{s} \\
\eta_{1} \\
w_{d} \\
\dot{w}_{s} \\
\dot{\eta}_{1} \\
\dot{w}_{d}
\end{array}\right\}+D\left\{\begin{array}{c}
f_{d} \\
V_{a}(t)
\end{array}\right\}
$$

where

$$
C=\left[\begin{array}{cccccc}
-1.46 e 12 & 1.55 e 13 & 0 & 0 & 0 & 0 \\
\frac{-3.8 e-3}{C_{\text {sensor }}} & \frac{4 e-2}{C_{\text {Sensor }}} & 0 & 0 & 0 & 0
\end{array}\right]
$$

and

$$
D=\left[\begin{array}{ll}
0 & 0 \\
0 & 0
\end{array}\right]
$$

The simulation, presented in Fig. 10, is performed with Matlab and its Control System Toolbox. The frequency value of the first natural bending mode is $4070 \mathrm{~Hz}$.

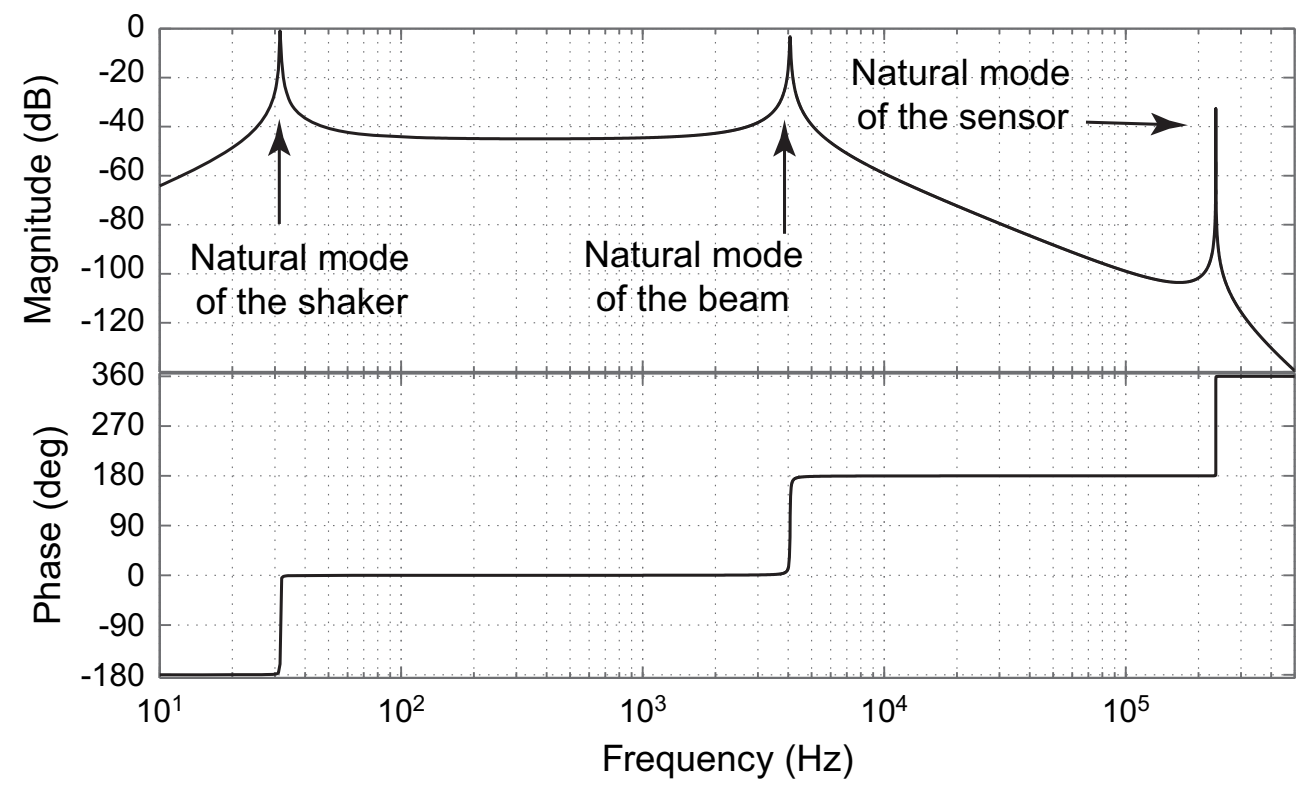

Fig. 10. Theoretical Bode diagram between the force applied to the shaker mass and the sensor output signal from the PVDF sensor. 


\subsection{Experimental characterization}

The objective of this section is to validate the analytical model of this system with an internal measurement provided by the sensor located under the mass to be isolated. For this, a random input voltage is applied to the actuators of the suspension device through a power amplifier and the sensor output signal is measured with a conditioning amplifier. A data acquisition process is used to obtain the experimental diagrams. The experimental characterization architecture is shown in Fig. 11.

In Fig. 12, the multiphysics model curve is compared with the experimental characterization curve, for validity. Both Bode diagrams are in good agreement and the prediction of the suspension frequency value is quite good. No tuning of the numerical model was performed. Only the capacitance value of the conditioning amplifier was modified to obtain a representative bode magnitude.

However, the low frequency behavior of the system is quite different. The presence of an electric zero in the physical system can explain this difference. Let us note the knowledge of the resonance peak is sufficient for our study. Some

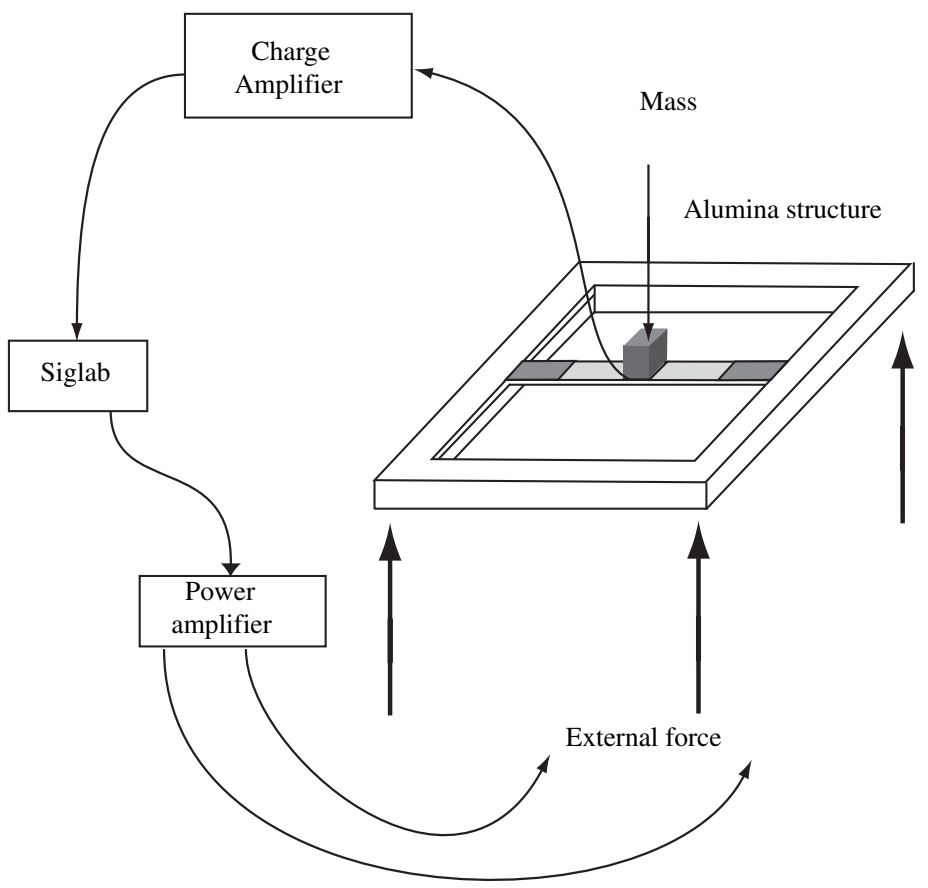

Fig. 11. Experimental characterization architecture.

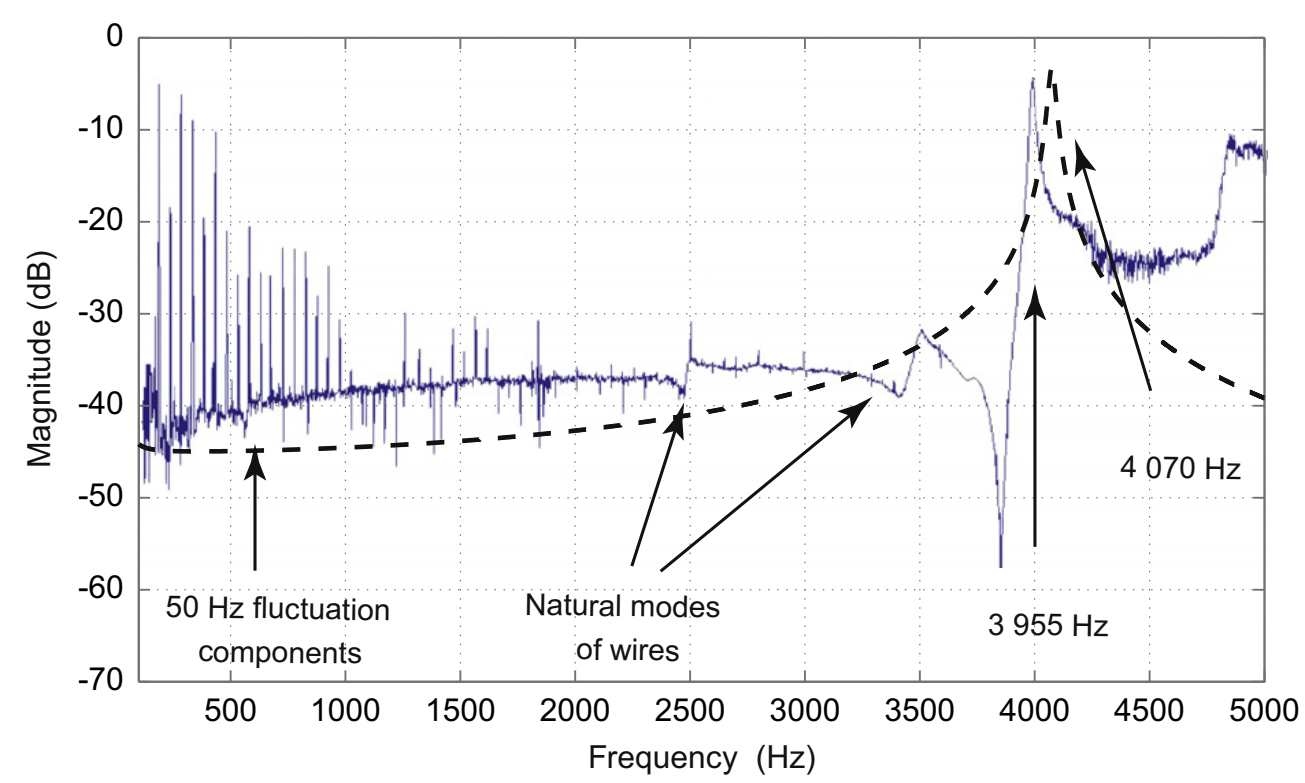

Fig. 12. Bode, measured (in solid line) and theoretical (in dotted line), diagrams between the force applied to the shaker mass and the sensor output signal. 
natural modes of wires are also observed. The $50-\mathrm{Hz}$ fluctuation components correspond to the French power supply frequencies.

\section{Active control of the structure}

\subsection{Control architecture and experimental setup}

The control strategy is based on a piezoelectric layer directly forced by the acceleration of the sensitive system to be isolated. The control process is described in Fig. 13. The controller input is the acceleration measurement. The control signal is amplified and applied to the piezoelectric actuating layers, making it possible to apply a mechanical control force to the system. Moreover, a data acquisition process is used to visualize and save the experimental results. The control system induces an active isolation along one-single-degree-of-freedom (the $Z$-axis).

As shown in Fig. 14, the experimental setup is composed of several elements. A Siglab data acquisition system with four input channels and two output channels is used for the data acquisition and signal processing. The device is shaked, along the $\vec{Z}$-axis via a shaker with a random vibration of $10 \mathrm{~g}_{r m s}$ amplitude $\left(\mathrm{g}_{r m s}=9.81 \mathrm{~m} \mathrm{~s} \mathrm{~s}_{r m s}^{2}\right)$. The reference signal is the PVDF sensor output signal. The sensor output signal is amplified with a conditioning amplifier. The input signal of the PZT actuators is amplified with a power amplifier. The control law is a simple proportional-integral feedback. This law is implemented with a DSpace ${ }^{\odot}$ platform whose the sampling frequency $\left(f_{\text {sampling }}=20000 \mathrm{~Hz}\right)$ is much higher than the

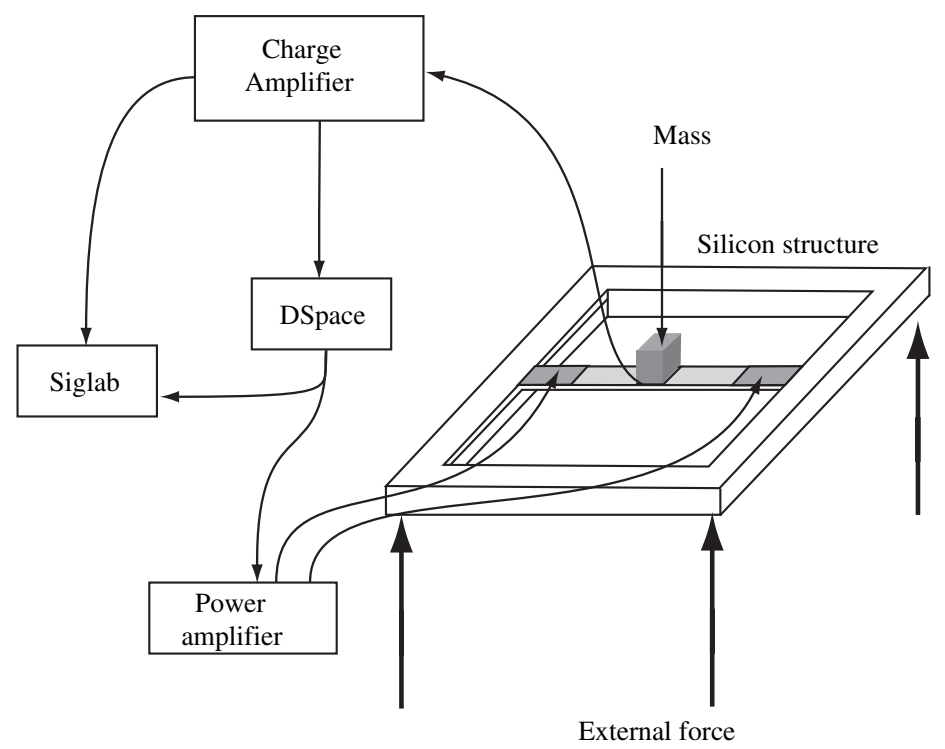

Fig. 13. Control architecture.

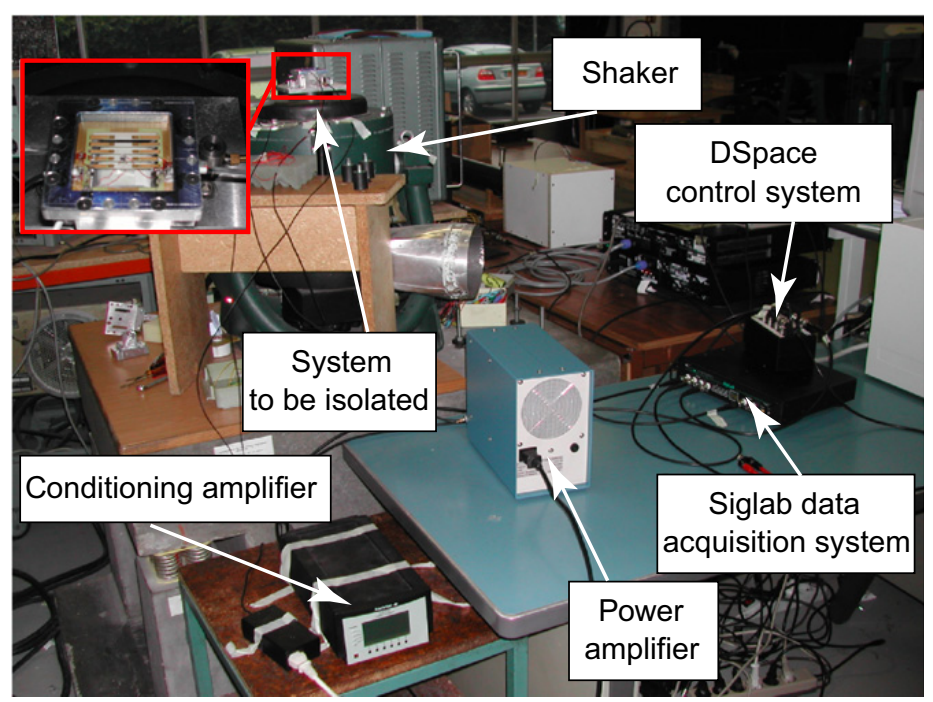

Fig. 14. Experimental control architecture. 
frequency of the mode to be damped (approximatively $3955 \mathrm{~Hz}$ ). However, the control line limits the control voltage to 200 V so as to avoid the PZT layer breakdown voltage.

\subsection{Numerical control results}

First, the active control is simulated so as to evaluate the theoretical suspension performances. It makes it possible to evaluate the isolation strategy properties. As shown in Figs. 15 and 16, the resonance peak attenuation is approximatively $-13.5 \mathrm{~dB}$ for an external excitation with a value of $10 \mathrm{~g}_{r m s}\left(\mathrm{~g}_{r m s}=9.81 \mathrm{~m} \mathrm{~s}_{r m s}^{2}\right.$ ) at the control voltage limit (200 V).

\subsection{Experimental control results}

In Fig. 17, the controlled and uncontrolled transfer functions between the sensor output signal and the force applied to the shaker mass are presented.

The controlled resonance peak is around $4250 \mathrm{~Hz}$ as predicted by the simulations. A $16 \mathrm{~dB}$ attenuation is observed for the resonance peak of the first suspension mode for an external excitation with a value of $10 g_{r m s}$. Let us note that another

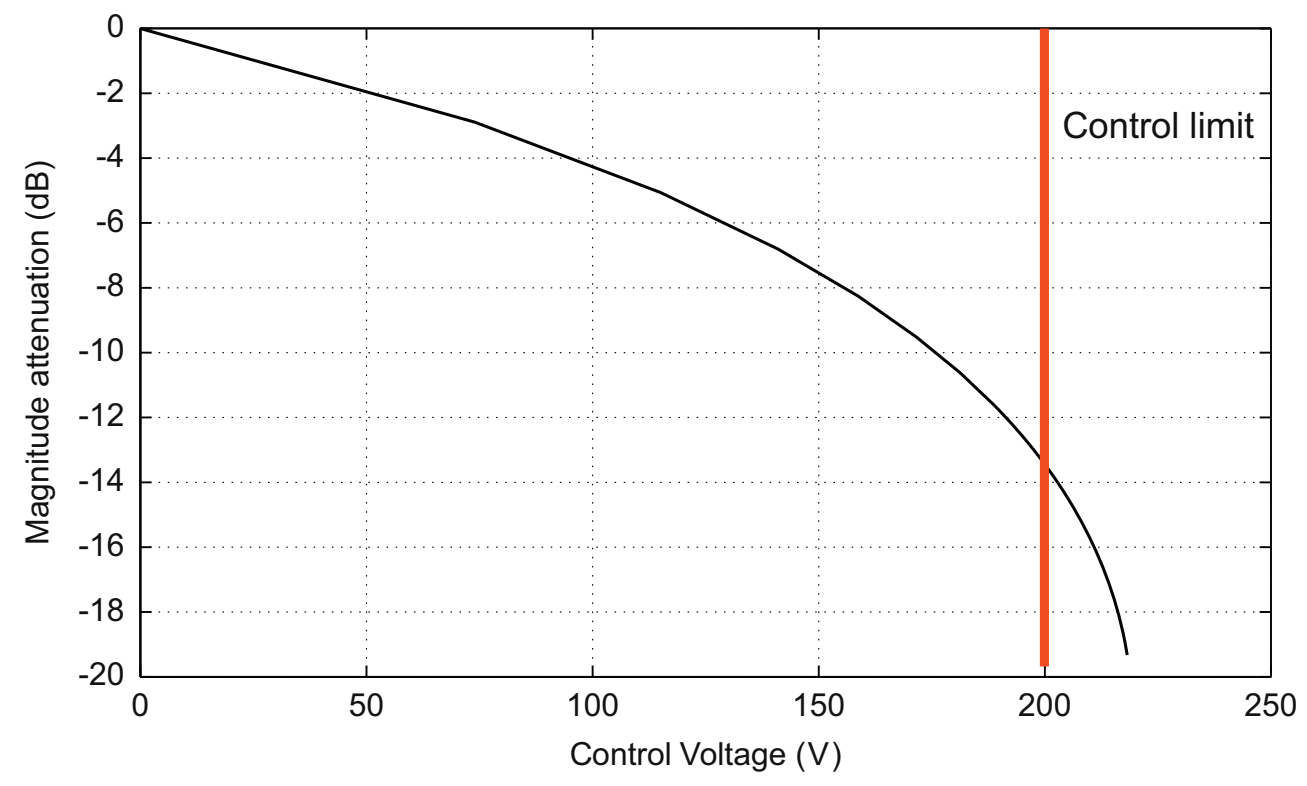

Fig. 15. Magnitude attenuation of the first bending mode with respect to the control voltage for the numerical control.

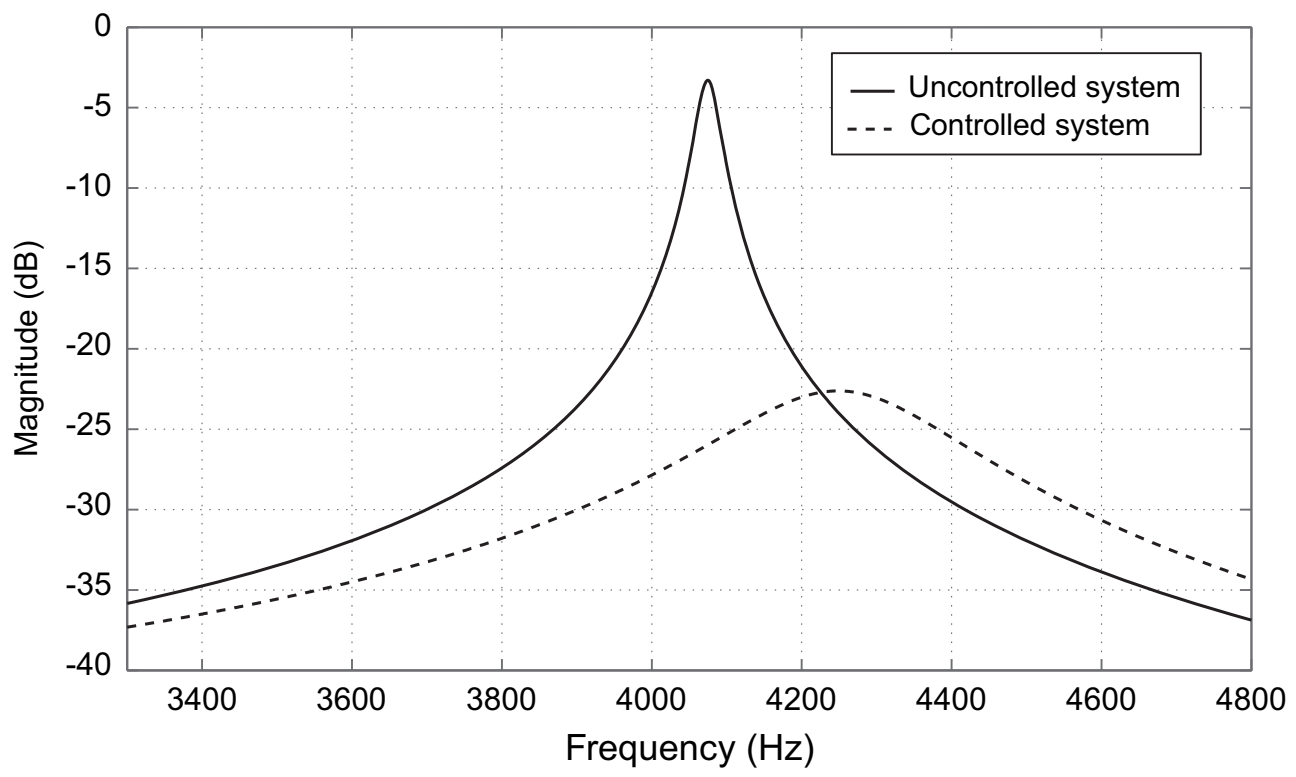

Fig. 16. Bode diagrams between the force applied to the shaker mass and the sensor output signal, without control (in solid line) and with the numerical control (in dotted line). 


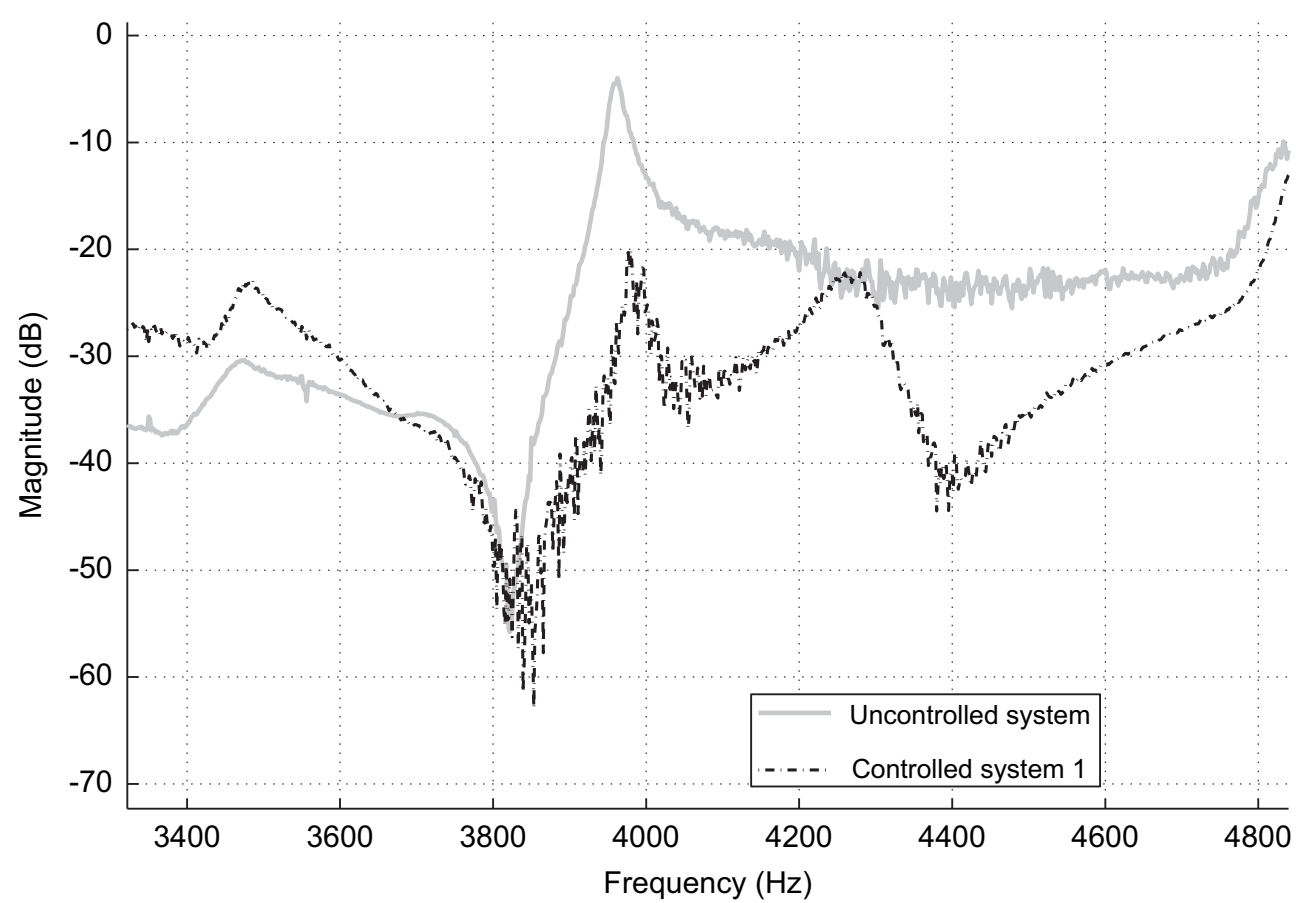

Fig. 17. Bode diagrams between the force applied to the shaker mass and the sensor output signal at the control voltage limit (200 V).

Table 3

Comparison between the numerical and experimental results for a $200 \mathrm{~V}$ control voltage.

\begin{tabular}{lcc}
\hline & Numeric results & Experiment \\
\hline Initial frequency $(\mathrm{Hz})$ & 4070 & 3950 \\
Controlled frequency $(\mathrm{Hz})$ & 4250 & 4270 \\
Attenuation $(\mathrm{dB})$ & -13.5 & -16 \\
\hline
\end{tabular}

"resonance" peak appears at $3950 \mathrm{~Hz}$. This fact is due to a residual coupling between the control law and the resonance peak. The control force, defined in Eq. (3), cannot be directly implemented in a DSP plate-form for the experiments. Indeed, the direct integration algorithm is not physically realizable because of poles located at 0 . So, a low pass filter, presented in Eq. (33), is introduced. Moreover, so as to limit the frequency bandwidth in which the vibration control is applied and so as to limit the control energy, a high-pass filter is introduced in the control loop.

Consequently, various transfer functions, in the Laplace's variables, are implemented in the DSP plate-form:

- an integration-type filter at first order:

$$
I(s)=\frac{G}{s+a}
$$

- a transfer function to limit control energy:

$$
P H(s)=\frac{s}{s+a}
$$

where $G$ and $a$ are, respectively, the control gain and a control design frequential parameter.

For the experiments, the best control performances with the limited control voltage are obtained for a frequential parameter very close to the resonance frequency $(3950 \mathrm{~Hz})$. Consequently, a little part of the resonance peak energy stays at $3950 \mathrm{~Hz}$.

Moreover, the sensor output signal is very noisy. In fact, the signal level is very low. Indeed, the control loop stabilizes the device to be isolated. Then, the PDVF layer which constitutes the sensor, is less forced. So, the noise level is quickly reached. In Table 3, the results obtained during the experiments are compared with the simulation for the suspension mode and the maximal control voltage.

Let us also note that a vibration increasing is observed after the suspension frequency. The studied device is an experimental and fatally imperfect structure. The fact that the electrical connections are not integrated induces some 
electric "parasitic" couplings. The authors assume that the increasing around $4850 \mathrm{~Hz}$ is due to an electric coupling. Indeed, the controlled mechanical resonance peak is at $4250 \mathrm{~Hz}$ as expected and just after this peak the high frequency decay is present. So, the vibration control operates onto the mechanical system. But, a limit is quickly reached and the curve-directing coefficient is modified and increases up to $4850 \mathrm{~Hz}$. This increasing is not really modified by the control. This observation can confirm that the phenomenon is not mechanical but electrical.

A difference of attenuation performances is noted. This may be due to the difference between the initial damping ratio, introduced in the modeling, and the experimental damping ratio. This experimental damping ratio is hard to be evaluated for this device type. However, the experimental and numerical results, listed in Table 3, are in good agreement. Moreover, the obtained attenuation is quite interesting for the "classical" military and aerospace applications.

\section{Concluding remarks}

In this paper, a new structural device is proposed to achieve the active vibration isolation of electronic components for military and aerospace applications. This device is based on an alumina clamped-clamped beam with PZT and PVDF transducing layers. The control law is based on an Integral Force Feedback control strategy.

The experimental results show an important resonance peak attenuation of the first bending mode of the system. For a random excitation with a $10 \mathrm{~g}_{\mathrm{rms}}$ amplitude and a 200 volts maximal control voltage, a 16-dB resonance peak attenuation is reached. The correct operation of the whole piezoelectric layers is thus shown. The trend and performances of the experimental control are in good agreement with the modeling.

\section{References}

[1] E.I. Rivin, Passive Vibration Isolation, ASME Press, New York, 2003.

[2] K.A. Williams, G.T. Chiu, R.J. Bernhard, Passive-adaptative vibration absorbers using shape memory alloys, in: N.M. Wereley (Ed.), SPIE Conference on Smart Structures and Integrated Systems, Newport Beach, USA, 1999, pp. 630-641.

[3] J.K. Knowles, R. Abeyaratne, On a shock-induced martensitic phase transition, J. Appl. Phys. 87 (1999) 1123-1134.

[4] R.A. Ibrahim, Recent advances in nonlinear passive isolators, J. Appl. Phys. 314 (2008) 371-452.

[5] A. Preumont, Vibration Control of Active Structures: An Introduction, Kluwer Academic Publishers, Dordrecht/Boston/London, 2002.

[6] D.C. Karnopp, A.K. Trikha, Comparative study of optimization techniques for shock and vibration isolation, Trans. ASME, J. Eng. Ind. 91 (1969) $1128-1132$.

[7] A. Preumont, A. François, F. Bossens, A. Abu-Hanieh, Force feedback versus acceleration feedback in active vibration isolation, J. Sound Vib. 257 (October) (2002) 605-613.

[8] J.E. Lagneses, J.-L. Lions, Modeling Analysis and Control of Thin Plates, Masson, Paris, 1988.

[9] C. Saravanan, N. Ganesan, V. Ramamurti, Semi-analytical finite element analysis of active constrained layer damping in cylindrical shells of revolution, Comput. Struct. 79 (2001) 1131-1144.

[10] B. Chomette, D. Rémond, S. Chesné, L. Gaudiller, Semi-adaptive modal control of on-board electronic boards using identification methods, Smart Mater. Struct. 17 (2008)

[11] Y. Meyer, T. Verdot, M. Collet, J. Baborowski, P. Muralt, Active isolation of electronic micro components with piezoelectrically-transduced silicon MEMS devices, Smart Mater. Struct. 16 (2007) 128-134.

[12] Ph. De Laminat, Automatique_Commande de Systèmes Linéaires, second ed., Hermes, Paris, 1996, p. 351

[13] Y. Meyer, M. Collet, P. Delobelle, Active damping of electronic microcomponents with piezoelectric MEMS devices, in: International Workshop on Smart Materials and Structures, Cansmart 04, Montréal, Canada, 2004.

[14] P. Monnier, M. Collet, J. Piranda, Definition of mechanical design parameters to optimize efficiency of integral force feedback, Struct. Control Health Monit. 12 (2005) 65-89.

[15] Y. Meyer, M. Collet, P. Delobelle, Primal-dual optimization process of IFF-DVF active damping strategies. Applications to the beams, Struct. Control Health Monit. 12 (2007) 660-680.

[16] V. Walter, P. Delobelle, P. Le Moal, E. Joseph, M. Collet, A piezo-mechanical characterization of PZT thick films screen-printed on alumina substrate, Sensors Actuators A 96 (2002) 157-166.

[17] H.J. Gesemann, L. Seffner, Preparation and application of PZT thick films, in: International Conference on Electroceramics and Applications, Electroceramics IV, vol. 1, 1994, pp. 317-320.

[18] A. Benjeddou, J.F. Deü, A two-dimensional closed-form solution for the free-vibrations analysis of piezoelectric sandwich plates, Int. J. Solids Struct. 39 (2002) 1463-1486.

[19] A. Fernandes, J. Pouget, Analytical and numerical approaches to piezoelectric bimorph, Int. J. Solids Struct. 40 (2003) $4331-4352$.

[20] C.K. Lee, F.C. Moon, Laminated piezopolymer plates for torsion and bending sensors and actuators, J. Acoust. Soc. Am. 85 (1989) $2432-2439$.

[21] C.K. Lee, Theory of laminated piezoelectric plates for the design of distributed sensors/actuators. Parts I and II, J. Acoust. Soc. Am. 87 (1990) 1144-1157.

[22] C.K. Lee, W.W. Chiang, T.C. O’Sullivan, Piezoelectric modal/actuator pairs for critical active damping vibration control, J. Acoust. Soc. Am. 90 (1991) 374-384.

[23] S. Timoshenko, Strength of Materials, third ed., Krieger Publishing Company, 1976. 